\title{
PREVIDÊNCIA SOCIAL BRASILEIRA um balanço da reforma
}

\author{
Rosa Maria Marques \\ Mariana Batich \\ Áquilas Mendes
}

\begin{abstract}
Resumo: Este texto faz uma análise exploratória do impacto da reforma na previdência social brasileira. Apesar de recente, esperava-se retração na demanda de benefícios, especialmente a de aposentadoria. Contudo, a evolução dos benefícios aponta para resultados não conclusivos, pois ainda se faz sentir a incerteza do período anterior. O artigo resgata, ainda, o significado da seguridade social na Constituição de 1988 e explora o contexto internacional e da América Latina.

Palavras-chave: reforma previdenciária; financiamento da previdência social; seguridade social.

Abstract: This text carries out an exploratory analysis of the impact of reform on the Brazilian social welfare system. Though attempts at reform are recent, an expectation was created for a decline in benefit demand, especially with regard to retirement benefits. However, results are inconclusive, due to uncertainties inherited from the past. This article goes on to examine the significance of social welfare in the 1988 Constitution and to explore the international and Latin American contexts.

Key words: welfare reform; financing of social welfare system; social welfare system.
\end{abstract}

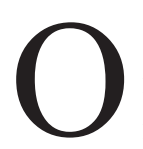

debate sobre a necessidade de alteração das regras de acesso à previdência social brasileira, bem como sua forma de financiamento, teve início quase que simultaneamente à votação da Constituição de 1988. Na época, o próprio governo, que havia criado o Grupo de Trabalho para embasar a reflexão e as propostas a serem discutidas na Constituinte, manifestava-se contrário à introdução do piso de um salário mínimo para os benefícios. Seu argumento era que a ampliação dos direitos no campo da proteção social e a concessão do piso de um salário mínimo a todos trabalhadores, inclusive aos rurais que até então não contribuíam, não tinham sido garantidas por um volume suficiente de recursos. Segundo sua avaliação, em um prazo muito curto, a previdência estaria imersa em problemática crise financeira.

Apesar das resistências governamentais, os constituintes, influenciados pelo ambiente político-social da abertura e com um discurso de que era preciso resgatar a enorme dívida social brasileira herdada do regime militar, aprovaram uma Constituição que procura garantir os direitos básicos e universais de cidadania, estabelecendo o direito à saúde, à assistência social, ao seguro-desempre- go e à previdência em um capítulo específico - da Seguridade Social.

O tratamento concedido ao campo da proteção social na Constituição de 1988 foi resultado da defesa realizada pelos setores progressistas que demandavam, na época, a construção de um sistema voltado a: ampliação da cobertura para segmentos até então desprotegidos; eliminação das diferenças entre trabalhadores rurais e urbanos referentes aos tipos e valores de benefícios concedidos; implementação da gestão descentralizada nas políticas de saúde e assistência; participação dos setores interessados no processo decisório e no controle da execução das políticas; definição de mecanismos de financiamento mais seguros e estáveis; e garantia de um volume suficiente de recursos para a implementação das políticas contempladas pela proteção social, entre outros objetivos.

Na realidade, alguns avanços visando a universalização, da ampliação da cobertura e a diminuição das desigualdades antecederam a Constituição de 1988. No que diz respeito à previdência, especificamente entre 1985 e 1987, o valor dos pisos dos benefícios urbanos foi aumentado, o prazo de carência, diminuído, e alguns tipos de benefícios foram estendidos para a clientela rural. Pode-se di- 
zer, contudo, que o amparo social definido pela Constituição significou a consolidação de um processo de discussão que vinha sendo realizado pela sociedade desde o final dos anos 70, no bojo da luta democrática.

\section{O AVANÇO DA CONSTITUIÇÃO DE 1988 E SEUS PRINCÍPIOS}

O conjunto de proposições, que garantiu a instituição do campo da seguridade social na Constituição, substituía o caráter meritocrático - o qual, até então, havia sustentado a proteção social, particularmente na área da previdência e na da saúde - pelo princípio da cidadania. Esse princípio, cabe lembrar, foi o mesmo que orientou a universalização da proteção social dos países capitalistas desenvolvidos, após a Segunda Guerra Mundial e mesmo durante os anos 70 e 80 . Ainda que as economias desses países começassem a apresentar problemas ao final da década de 70, principalmente devido à retração do crescimento econômico, à elevação das taxas de desemprego, ao surgimento de déficits fiscais e ao aumento do nível de preços, os sistemas de proteção social ampliaram seu campo de ação, incorporando novos segmentos em sua cobertura. Os exemplos mais característicos dessa fase são: o fato de passar a ser reconhecido como desempregado o trabalhador sem emprego que nunca trabalhou e o surgimento de programas de renda mínima, animados pelo princípio da cidadania e não entendidos como uma mera ação assistencial.

Para garantir os direitos do cidadão no campo da seguridade social, os constituintes estabeleceram um esquema de financiamento com recursos provenientes dos orçamentos das áreas federal, estadual e municipal, e de contribuições sociais, calculadas sobre o salário, o faturamento e o lucro líquido (art. 195 da Constituição Federal).

Saliente-se que os constituintes também defendiam que as fontes de financiamento da seguridade social não seriam distintas de seu conceito. Em outras palavras, consideravam, ao ser eleita a cidadania e não o mérito como a referência para o direito à proteção social, estabelecido que a sociedade deveria, a cada ano, discutir e definir de que forma seria realizada a partilha do conjunto de receitas previstas para a seguridade social. Isso significa dizer que os constituintes se colocaram contra o estabelecimento de vinculação de receitas no interior da seguridade social. A única exceção ficou por conta do PIS/Pasep, que passou a ter uso exclusivo do programa seguro-desemprego e do pagamento do abono PIS/Pasep, sendo $40 \%$ de sua arrecadação destinada a empréstimos realizados pelo BNDES às empresas.

\section{O AMBIENTE INTERNACIONAL E DA AMÉRICA LATINA}

O debate acerca da reforma da previdência social, nos anos 90, insere-se na discussão realizada internacionalmente sobre o futuro da proteção social. Entre os constrangimentos que justificavam essa preocupação, destacava-se a manutenção de altas taxas de desemprego nos países capitalistas avançados, o que comprometia a arrecadação das receitas de contribuição de empregados e empregadores e o aumento da despesa com o seguro-desemprego e programas de renda mínima. Além disso, muitos regimes de previdência começaram a apresentar problemas na relação contribuintes/beneficiários, não só como reflexo da nova situação do mercado de trabalho, como também pela tendência ao envelhecimento da população que já se manifestava mesmo antes da crise surgir. Para complicar ainda mais a situação financeira dos sistemas de proteção social e, por decorrência, da previdência, outra tendência observada desde os anos 60 continuava a preocupar: o aumento crescente dos gastos com saúde.

Num primeiro momento, para manter o equilíbrio financeiro, os países avançados criaram, durante os anos 80, vários procedimentos: a) aumento das contribuições sociais; b) maior participação dos usuários nas despesas com assistência médica; c) incentivo à complementação da aposentadoria através de entidades privadas; d) estreitamento da variação do valor da aposentadoria, reajustando aquelas com valores mais baixos em detrimento daquelas de níveis mais elevados (Marques e Médici, 1994). Ao mesmo tempo, tiveram a preocupação de implementar políticas que garantissem mínimos de renda e aumentaram a participação do Estado no financiamento da proteção social. A garantia de mínimos fica evidente quando se acompanham as reformulações efetuadas no seguro-desemprego, principalmente na França. Nesse país, inicialmente foi introduzido um benefício de baixo valor para os desempregados de longa-duração - que tinham esgotado o tempo de permanência no seguro-desemprego "normal"- e para os desempregados que sequer chegaram a entrar no mercado de trabalho. Depois, foi criada a Renda Mínima de Inserção - RMI, programa que preten- 
dia, mediante concessão de renda mínima, criar as condições do trabalhador voltar ao (ou ingressar no) mercado de trabalho. A permanência do trabalhador no programa, pensada inicialmente como temporária, demonstrou-se, contudo, permanente devido à continuidade das altas taxas de desemprego.

Nos anos seguintes, apesar da adoção de novas medidas, tais como o aumento da idade para a concessão da aposentadoria e tratamento igual para os gêneros em alguns países, pode-se dizer que, nos anos 90, nos países europeus de forte tradição sindical, a proteção social pública, universal e sob regime de repartição continuou sendo o principal sistema de apoio existente. ${ }^{1}$ Cabe assinalar que o benefício-base concedido por esses sistemas é socialmente reconhecido como suficiente para responder às necessidades dos segurados e a diversidade de benefícios é bastante reduzida quando se tem presente a variação entre um e dez salários mínimos que havia no sistema brasileiro. Por outro lado, nesses países, os sistemas complementares de caráter facultativo sempre foram significativos, tornando-se mais fortes nos últimos anos, principalmente em função da alta rentabilidade de suas aplicações no setor financeiro.

$\mathrm{Na}$ América Latina, no entanto, onde a proteção social em geral sempre foi precária, não atingindo o conjunto da população e, muitas vezes, não constituindo um sistema unificado e sim formado de diversos regimes de base corporativa, a história da reforma foi diferente. Vários países, reféns da dívida externa e constrangidos pelo fraco crescimento econômico, seguiram os ditames e as metas do Fundo Monetário Internacional, promovendo reformas ao gosto neoliberal em seus sistemas de proteção social. Desnecessário dizer que essas reformas, defendidas em geral pelos representantes do Banco Mundial, do FMI e agências internacionais, nunca foram colocadas em prática nos países avançados. Para se ter uma idéia, depois que o Chile, em 1982, privatizou a previdência social, outros sete países do continente - Bolívia, El Salvador, México, Peru, Colômbia, Argentina e Uruguai introduziram reformas no sentido da privatização e da capitalização, ainda que seguindo modelos gerais diversos e com importantes diferenças na sua implantação. Esses países seguiram as recomendações do Banco Mundial, expressas em especial no documento "Envelhecer sem crise" (Dieese, 2001).

É nesse contexto - internacional e da América Latina - que se insere a discussão da reforma da previdência social brasileira.

\section{O QUESTIONAMENTO DA CONSTITUIÇÃO E OS ARGUMENTOS DA REFORMA}

A partir dos anos 90, a crescente crise fiscal-financeira do Estado, o fraco desempenho da economia e o crescimento da taxa de desemprego e do trabalho informal propiciaram o fortalecimento do discurso sobre a necessidade de reformar a previdência social. Entre os vários argumentos, um dos que se destacavam defendia que os direitos introduzidos pela Constituição de 1988 teriam provocado fortes desequilíbrios no sistema previdenciário. Vários especialistas - ainda que não concordassem com esse argumento - exigiam mudanças levando em conta a persistência de tratamento desigual entre diferentes categorias de trabalhadores ou os impactos provocados pelas alterações no perfil demográfico e na transformação da relação entre capital e trabalho, decorrente da adoção das novas tecnologias e formas de gestão no sistema produtivo brasileiro.

Em meados dos anos 90, as mais de 20 propostas em discussão sobre a reformulação da seguridade social e da previdência já podiam ser reunidas em duas grandes vertentes: as que consideravam a proteção social como tarefa do Estado e as que a compreendiam como responsabilidade individual do cidadão. Essa última, situada claramente no campo neoliberal, justificava que somente adotando um sistema privado e de capitalização as pessoas teriam estímulo para melhorar seu rendimento e, por conseqüência, aumentarem sua capacidade de poupança, criando as bases necessárias para a sustentação financeira do desenvolvimento do país. Coerentes com essa visão, defendiam que o financiamento deveria ser unicamente sustentado pelo trabalhador/indivíduo. Dessa forma, seria eliminado - no entender dessa perspectiva - o desestímulo à contratação no mercado de trabalho, pois os encargos sociais seriam ou eliminados de todo ou sensivelmente diminuídos, o que permitiria aumentar a competitividade dos produtos brasileiros no mercado internacional, aumentando as exportações. Além disso, como reconhecem que o mercado não é totalmente perfeito, de forma que alguns indivíduos são submetidos a situações de carência, admite a ação assistencial do Estado, financiada através da receita de impostos.

Entre as propostas que defendiam a manutenção do Estado como responsável pela organização e gestão da proteção social, vale destacar as do deputado Eduardo Jorge, a da Comissão Especial para o Estudo do Sistema Previdenciário - cujo relator foi Antônio Brito (depois 
Ministro da Previdência Social) - e a proposta de Reinhold Stephanes. Essas e todas as outras propostas que preservavam o papel-chave do Estado na previdência social, embora fossem unânimes em sugerir que o financiamento continuasse a ser realizado através de contribuições de empregadores e empregados, defendiam a diversificação das fontes. Isso porque tinham como objetivo compensar o fraco desempenho das contribuições sobre a folha de salários, e até mesmo reduzir a carga contributiva das empresas, visando estimular a contratação de trabalhadores no mercado formal. De maneira diferenciada, as propostas defendiam vários tetos para os benefícios concedidos pelo setor público e algumas chegavam a propor a adesão compulsória a um regime complementar. Era consenso, contudo, a extinção da aposentadoria por tempo de serviço e da aposentadoria especial.

Ainda entre aqueles que defendiam a manutenção da previdência pública, havia o debate sobre a pertinência ou não da criação de um sistema previdenciário único, integrando os funcionários públicos federais - bem como os do Judiciário, Forças Armadas, entre outros - e os demais trabalhadores. Essa proposta sofreu forte repúdio por parte dos funcionários públicos, dos sindicatos e da Central Única dos Trabalhadores.

\section{BASES DOS PRINCIPAIS ARGUMENTOS DA REFORMA PREVIDENCIÁRIA}

No início da discussão sobre a necessidade de reforma, ficou quase chavão dizer que seus problemas derivavam de problemas de caráter estrutural, conjuntural e gerencial, e que havia uma estreita relação entre eles.

Entre os problemas apontados como estruturais, destacava-se a baixa relação contribuintes/segurados. ${ }^{2}$ De fato, todos os regimes de repartição passam pela seguinte trajetória: inicialmente apresentam uma relação positiva extremamente alta, pois é crescente a entrada de contribuintes no sistema e o pagamento de benefícios se restringe à aposentadoria por invalidez e à pensão por morte. $\mathrm{Na}$ maturidade, no entanto, quando parcela significativa de seus contribuintes alcança a idade mínima para requerer aposentadoria ou cumpre a carência de contribuição, essa relação decresce de forma significativa.

A queda dessa relação é ainda mais acentuada quando concorrem dois outros fatores, tal como acontece no Brasil: o aumento crescente da expectativa de sobrevida das pessoas que se aposentam e a redução do número de trabalhadores ativos devido à crise econômica prolongada e/ou à mudança da relação entre capital e trabalho em função do uso de novas tecnologias e novas formas de gestão. No caso brasileiro, ainda, a baixa capacidade fiscalizatória do Estado - em parte decorrente da crise fiscal e financeira dos anos 90 - favoreceu a ampliação do mercado informal de trabalho, com evidente perda de arrecadação de contribuições sociais.

Dentre os fatores "conjunturais", eram destacados o baixo crescimento das contribuições previdenciárias e o aumento das despesas com benefícios, explicados pelo fraco desempenho da economia e pelo crescimento da demanda de caráter assistencial. Em relação aos aspectos "gerenciais", o argumento geralmente atribuía à gestão pública adjetivos como precária, burocratizada e ineficiente, o que resultava em altos custos operacionais e no elevado número de fraudes e de sonegação.

\section{A REFORMA NO GOVERNO FHC}

Em março de 1995, o governo FHC apresentou ao Poder Legislativo proposta de alterações do sistema previdenciário brasileiro, abrangendo o setor privado e o público, compreendendo os funcionários públicos civis, militares e a magistratura. Essa proposta baseava-se em sua compreensão da situação e da evolução do comportamento das contas públicas, da economia e da demografia, e de seus efeitos sobre o sistema previdenciário do país. Os fatores que constrangiam as contas da previdência social são resumidamente apresentados nos parágrafos seguintes.

Na década de 90, as fontes tradicionais de suprimento dos gastos públicos - o aumento de impostos e o endividamento do Estado - não tinham como continuar a ser utilizadas para propiciarem aumento de receitas. A conjuntura econômica interna em favor da estabilidade da moeda e as pressões externas, especialmente do FMI, para a contenção do déficit público constituíam um poderoso freio à utilização desses meios.

Além dos problemas de ajuste do orçamento estatal, a sociedade brasileira passou a conviver com altas taxas de desemprego, causadas pela deterioração econômica, iniciada na década de 80 , e aprofundada com a abertura do mercado brasileiro à importação de produtos estrangeiros, com a política de juros elevada e com a âncora cambial que acompanhou a entrada do real; e pela introdução de inovações tecnológicas. O aumento do desemprego foi acompanhado da diminuição do número de trabalhadores com carteira assinada e do aumento da quantidade dos que 
se dirigiram para a informalidade. Como somente aqueles são obrigados a contribuir para a previdência, garantindo os recursos necessários para fazer frente às despesas com os benefícios previdenciários, a diminuição de trabalhadores registrados no mercado de trabalho provocou queda dos rendimentos do caixa da previdência pública ou um desempenho bastante medíocre, não só incompatível com a evolução das décadas anteriores, como insuficiente para fazer frente às despesas.

O equilíbrio das contas previdenciárias também passou a ser prejudicado pelas transformações em curso da estrutura demográfica do Brasil, argumento que já era utilizado na defesa da reforma da previdência social no período imediatamente anterior ao governo FHC. Uma das transformações refere-se ao aumento da expectativa de vida da população, reflexo do avanço técnico-científico que atinge a todos os povos, independentemente do seu grau de desenvolvimento, permitindo o prolongamento, cada vez maior, do número de anos de vida da população adulta. A outra se refere à queda da taxa de crescimento da população devido à diminuição da taxa de fecundidade, causada pelas transformações econômicas e sociais do mundo moderno e o avanço de métodos contraceptivos.

Como dito anteriormente, o sistema previdenciário brasileiro está baseado na repartição simples, isto é, são os atuais membros da população em idade ativa, através de suas contribuições previdenciárias, que garantem os recursos para pagamento dos benefícios, esperando que as gerações futuras, com suas contribuições, façam o mesmo. Diante do comportamento demográfico brasileiro apontado acima e explorado mais adiante, alterou-se a taxa de dependência da população aposentada em relação à população ativa, o que poderia colocar em risco o sistema público de previdência.

Algumas propostas governamentais, para serem aprovadas, deveriam ser antecedidas por mudanças nas disposições da Constituição de 1988, enquanto outras não feriam princípios da Carta Magna. Por esse motivo, entre 1994 e 1996, foram extintos alguns tipos de benefícios destinados aos trabalhadores do setor privado, como o abono, o pecúlio, os auxílios natalidade e funeral, ${ }^{3}$ e limitada a concessão das aposentadorias especiais. ${ }^{4}$

Embora o Poder Executivo tivesse colocado em discussão a reforma da previdência já no princípio dos anos 90 - mal tinham sido decretadas as Leis oㅜ 8.212 e no 8.213, que regulamentavam respectivamente o custeio e os benefícios previdenciários, segundo as determinações da Constituição de 1988 -, somente em 1995 tomou as pro- vidências para mudar os dispositivos constitucionais que permitiriam as mudanças que considerava necessárias. Assim, em março de 1995, apresentou ao Congresso Nacional a proposta de emenda constitucional conhecida como PEC 33. As discussões a respeito ficaram em pauta até julho de 1996. Devido às repercussões negativas que suscitou em relação a alguns aspectos da proposta, sofreu reformulações, sendo reapresentada em 1997. No dia 15 de dezembro de 1998, finalmente foi aprovada a Emenda Constitucional no 20 .

Uma das alterações do sistema previdenciário que exigiam mudança na Constituição referia-se à imposição de um limite de idade para obtenção da aposentadoria por tempo de serviço, a fim de impedir a crescente participação de pessoas com idade inferior a 50 anos no sistema de benefícios, embora apresentassem todas as condições de continuar sua vida ativa. Essa proposta, entre todas encaminhadas pelo governo, foi a que mais causou polêmica e divulgação pela mídia no período de discussão da reforma, uma vez que sua alteração iria atingir tanto os trabalhadores do setor privado como do setor público.

Em relação ao sistema previdenciário dos trabalhadores do setor privado, foco desse estudo, ${ }^{5}$ os dispositivos da Constituição de 1988 levados à revisão e aprovados pela Emenda Constitucional no 20 foram: a eliminação do teto de dez salários mínimos para o pagamento dos benefícios das aposentadorias por tempo de serviço e das regras de cálculo desse benefício (média aritmética dos últimos 36 meses); e a criação de condições para que o sistema público de previdência siga regras que proporcionem o equilíbrio financeiro e atuarial.

Com a aprovação da EC no 20 , a Constituição passa a determinar que o segurado, para ter direito à aposentadoria, contribua no mínimo durante 35 anos, se homem, ou 30, se mulher. No caso da aposentadoria por idade, o homem necessita ter 65 anos e a mulher, 60 . Permaneceu a redução de 5 anos para os rurais de ambos os sexos e para o professor que "comprove exclusivamente tempo de efetivo exercício das funções de magistério na educação infantil e no ensino fundamental e médio" (art.201, parágrafos 7oㅡ, inciso l e II, e 8o). Graças aos novos dispositivos constitucionais, a partir de dezembro de 1998 o governo pôde então elaborar leis ordinárias permitindo mudanças no sistema previdenciário e normas para a transição das antigas determinações legais para as novas.

A Lei no 9.876/99, apresentada ao Congresso Nacional e que vai de fato regulamentar as disposições constitucio- 
nais e provocar a reforma da previdência para os trabalhadores do setor privado, apresentava medidas visando: - à ampliação do período de cálculo do benefício;

- à introdução de uma fórmula de cálculo deste benefício que considera a idade de quem requisita a aposentadoria e a expectativa de vida segundo cálculos do IBGE;

- à eliminação gradativa da escala de salários-base dos contribuintes individuais; e

- à homogeneização do valor de contribuição das empresas ao tratar das diversas categorias de segurados obrigatórios. Introduz, ainda, no campo gerencial, a diferenciação entre o contribuinte inadimplente e o sonegador; a redução dos juros de mora para $0,5 \%$ ao mês, mais capitalização anual, para a indenização do tempo de serviço passado; e a generalização do pagamento direto, por parte do INSS, de todo salário-maternidade, o que em parte anteriormente era realizado pelo empregador, mediante reembolso. A proposta do governo foi aprovada pelo Congresso Nacional em 26 de novembro de 1999.

Uma das alterações mais significativas introduzidas pela reforma foi a do valor do benefício de aposentadoria. No caso das aposentadorias por tempo de contribuição, no lugar desse valor ser estabelecido pela média aritmética dos últimos 36 (trinta e seis) meses de contribuição, passou a considerar a média aritmética simples dos maiores salários de contribuição correspondentes no mínimo a 80\% de todo o período contributivo do segurado, corrigidos monetariamente. Sobre esse cálculo é aplicado um fator redutor que varia de acordo com a idade do segurado, ou seja, o quanto de vida ele terá depois de aposentado, segundo estimativas da Fundação IBGE. Esse fator foi denominado Fator Previdenciário. ${ }^{6}$

Apesar da nova lei determinar o cumprimento do tempo de contribuição (35 para homem e 30 anos para mulher), quem estava inscrito na Previdência Social até 15/ 12/1998 (véspera da publicação da Emenda Constitucional no 20, de 1998) "também pode se aposentar aos 25 e 30 anos de contribuição, respectivamente, se do sexo feminino ou masculino, desde que tenha 48 ou 53 anos de idade. Nesse caso o valor do benefício será de $70 \%$ do salário de benefício acrescido de 5\% por cada grupo de 12 contribuições adicionais, até o limite de 100\%"(MPAS, 1999:13).

Em relação ao fator, vale a pena destacar a seguinte interpretação: "Sem ter incorporado a proposta de limite mínimo de idade para a aposentadoria dos já inscritos no sistema (60 anos para mulheres e 65 anos para os homens), previsto originalmente pelo executivo quando do envio da PEC no 20 [...] a nova legislação previdenciária optou pelo incentivo à permanência em atividade do trabalhador, mediante uma modalidade de cálculo em que o benefício é diminuído caso ele seja jovem ou tenha pouco tempo de contribuição, mas que aumenta à medida que a concessão da aposentadoria é adiada" (Dieese, 2001:252).

De acordo com Solange Paiva Vieira, mentora da fórmula de cálculo do fator previdenciário, assessora especial do MPAS, em entrevista à revista Conjuntura Econômica: "Fiz então a conta de trás para frente, com variáveis como a expectativa de vida, fluxo de caixa, tempo de contribuição e a taxa de juros implícita. Eu peguei tempo de contribuição por expectativa de sobrevida e multipliquei o tempo de contribuição pela alíquota contributiva.[...] A gente fez uma captação virtual. [...] É uma capitalização [...] tem uma capitalização com uma taxa de juros que varia entre $2,5 \%$ e $4,5 \%$. Taxa real, dependendo da idade em que a pessoa se aposenta. Está lá, é o que a pessoa contribui, corrigido por essa taxa de juros ao ano" (FGV, 2001:58).

Para o segurado que até 28 de novembro de 1999 tenha cumprido as condições para solicitar a concessão da aposentadoria, será considerada somente a média aritmética simples das maiores contribuições, correspondentes a, no mínimo, $80 \%$ de todo o período contributivo decorrido desde a competência julho de 1994.

Segundo o governo, essas alterações permitiriam que o caixa da previdência se equilibrasse por alguns anos, embora não descartasse a adoção de novas modificações, caso fosse necessário.

\section{A SITUAÇÃO FINANCEIRA PÓS-REFORMA}

\section{A Persistência do Déficit}

Segundo o Ministério da Previdência e Assistência Social - MPAS, a previdência social fechou o primeiro ano pós-reforma com um déficit de $\mathrm{R} \$ 10,07$ bilhões, equivalente a $0,9 \%$ do Produto Interno Bruto - PIB. ${ }^{7}$ Esse resultado foi considerado bastante satisfatório, pois estava sendo a primeira vez que o déficit, enquanto proporção do PIB, registrava queda em cinco anos. Contudo, em 2001, o déficit novamente aumentou (R \$ 12,8 bilhões), representando $1,08 \%$ do PIB.

Antes de serem analisados os fatores que contribuíram para os resultados dos anos 2000 e 2001, bem como o impacto das mudanças promovidas no campo dos benefícios e das contribuições pela reforma promovida pelo 
governo Fernando Henrique Cardoso, merece um pouco mais de atenção o conceito de déficit utilizado pelo MPAS.

Para isso é preciso lembrar que a previdência social é parte integrante da seguridade social, rede de proteção idealizada por aqueles que participaram da elaboração e votação da Constituição cidadã, como a chamou Ulisses Guimarães, quando da sua aprovação pelo Congresso Nacional. Essa rede, através da Previdência Social, da Saúde, da Assistência Social e do Programa de Seguro-Desemprego, garante a concessão de benefícios em situação de aposentadoria, de desemprego, de perda de capacidade laboral ou doença e de necessidade de complementação de renda; e a realização de ações e serviços preventivos e curativos relacionados ao risco doença.

Para garantir os recursos necessários, os constituintes reservaram o uso exclusivo do resultado da arrecadação das contribuições incidentes sobre a folha de salários, faturamento, lucro, concursos e prognósticos, além de preverem a participação do governo federal, dos Estados e dos municípios. Vale lembrar, ainda, que a Constituição de 1988 não estabelecia vinculação no interior da seguridade social, com exceção dos recursos do PIS-Pasep que sempre foram destinados ao financiamento do Fundo de Amparo do Trabalhador - FAT, responsável pela concessão do seguro-desemprego. Com o passar do tempo, veio se somar a essas fontes de recursos a contribuição sobre movimentação financeira e foi definida a participação das três esferas de governo no financiamento da saúde.

Considerando esse conceito de proteção social, não seria apropriado calcular isoladamente as contas da previdência social, tal como previsto na Lei de Responsabilidade Fiscal. ${ }^{8}$ Como será argumentado mais adiante, seu resultado negativo é reflexo, antes de tudo, do desempenho da economia brasileira que, se voltasse a crescer e a gerar emprego no mercado formal de trabalho, superaria rapidamente sua situação de déficit. Essa argumentação não desconsidera, entretanto, que, em termos contábeis, seja apurado o resultado da previdência social. O que se estranha é o fato de o governo federal nunca se preocupar em contabilizar e divulgar para toda a sociedade o resultado do conjunto da seguridade social. Em 1999, por exemplo, ano em que a reforma foi aprovada e a previdência registrava um déficit equivalente a $1 \%$ do PIB, a seguridade social apresentava um superávit de R\$ 16, 3 bilhões, correspondendo a 1,7\% do PIB. Em 2001, adotando-se o mesmo critério, o superávit da seguridade social aumentou para R\$32,1 bilhões, cerca de 2,6\% do PIB. A Tabela 1 apresenta o resultado da seguridade social no ano de 2001.

\section{O Comportamento da Despesa e o Fator Previdenciário}

O gasto com benefícios caiu no primeiro ano pós-reforma $(-1,04 \%)$ em relação ao ano anterior, voltando a subir em 2001 (2,84\%). A queda observada em 2000 havia sido comemorada, pois era a segunda vez consecutiva que isso ocorria: em 1999, portanto antes da reforma ser aprovada, a despesa com benefícios havia diminuído em $1,63 \%$, o que constitui forte indício de que o decréscimo

TABELA 1

Receitas(1), Despesas e Saldo da Seguridade Social Brasil - 2001

Em bilhões de reais

\begin{tabular}{lr}
\hline Especificações & Valor (R\$) \\
\hline TOTAL DAS RECEITAS & 137,52 \\
Receita Previdenciária Líquida (2) & 62,491 \\
Outras Receitas do INSS (3) & 0,618 \\
Contribuição para Financiamento da Seguridade Social - Cofins & 46,704 \\
Contribuição Social sobre o Lucro Líquido & 9,067 \\
Concursos e Prognósticos & 0,521 \\
Receita Própria do Ministério da Saúde & 0,962 \\
Outras Contribuições Sociais (4) & - \\
Contribuição Provisória sobre Movimentação Financeira - CPMF & 17,157 \\
TOTAL DAS DESPESAS & 105,413 \\
Benefícios & 78,697 \\
a) Previdenciários (5) & 73,692 \\
- Urbanos & 59,383 \\
- Rurais (6) & 14,309 \\
b) Assistenciais & 4,323 \\
- Rendas Mensais Vitalícias - RMVs & 1,636 \\
- Lei Orgânica de Assistência Social - Loas & 2,687 \\
C) Encargos Públicos da União - EPU (7) & 0,682 \\
Saúde (8) & 21,111 \\
Assistência Social & 1,875 \\
Custeio e Pessoal do Ministério da Previdência e & \\
Assistência Social - MPAS (9) & 3,497 \\
Ações do Fundo de Combate à Pobreza & 0,233 \\
SALDO (Receitas Menos Despesas) & 32,107 \\
\hline Fonte Mnistio da Fazena. Secrea
\end{tabular}

Fonte: Ministério da Fazenda. Secretaria do Tesouro Nacional. Sistema Integrado de Administração Financeira do Governo Federal - Siafi, 2000 e 2001(dados preliminares); Ministério da Previdência e Assistência Social - MPAS. Fluxo de Caixa do INSS; Associação Nacional dos Auditores Fiscais da Previdência - Anfip.

(1) Conforme preceitua o artigo 195 da C.F.

(2) Inclui: arrecadação bancária, o Simples e depósitos judiciais.

(3) Segundo o fluxo de caixa do INSS, incluem rendimentos financeiros e antecipações de receitas e outros.

(4) Dado não disponivel que incluiria: o Depósito Obrigatório de Veículos Auto-Motores-DPVAT; a renda bruta de prêmios prescritos; e bens apreendidos.

(5) Difere do Fluxo de Caixa do INSS (que somou $R \$ 75,378$ bilhões) devido à separação das RMVs em item próprio.

(6) Dados sujeitos a alteração.

(7) Encargos previdenciários da União devido à concessão de benefícios através de leis especiais, pagos pelo INSS com recursos da Seguridade, e repassados pelo Tesouro.

(8) Inclui despesas de saneamento, de custeio e ações de saúde do Sistema Único de Saúde - SUS do Ministério da Saúde.

(9) Pagamentos realizados a ativos, inativos e pensionistas do INSS, bem como despesas operacionais consignadas. 
ocorrido no primeiro ano depois da reforma deve-se também a outros fatores, que não aqueles diretamente relacionados com as novas regras.

É sabido que a nova lei não tem nenhum impacto sobre aqueles que já recebem benefícios, o que no jargão da previdência social é chamado de estoque de benefícios. As novas regras são aplicadas integralmente àqueles que, depois de sua edição, ingressarem no mercado de trabalho, e as de transição, para aqueles que já participavam do mercado formal de trabalho e, portanto, contribuíam para a previdência sob as regras anteriores. Nesse sentido, no curto prazo, já seria esperado que o impacto da reforma sobre o volume do gasto fosse pequeno, mas que atuasse diminuindo a taxa de ingresso de novos segurados no sistema, particularmente de aposentados.

Contudo, a evolução dos benefícios concedidos em período recente, que traduz a demanda efetivamente realizada de novos segurados, apresenta comportamento que não se pode, a princípio, dizer que está refletindo o impacto das novas regras. O ingresso de novas aposentadorias - de todos os tipos - já vinha caindo desde antes mesmo da reforma. Entre 1997 (846.168) e 2001 (560.212), segundo dados do MPAS, o número de concessões decresceram 33,8\%. Destaque-se que o número do último ano, foi o mais baixo da década excluindo-se o de 1991 (455.533), quando a demanda encontrava-se represada, esperando a regulamentação dos novos direitos previdenciários aprovados pela Constituição de 1988.

Fica difícil dizer se o desempenho observado em 2001 (redução de 16,5\%) já é reflexo das novas regras ou mesmo se expressa o crescimento vegetativo da demanda de benefícios de aposentadoria da previdência social. Isso porque, desde 1986, os dados anuais relativos à aposentadoria e aos demais benefícios programáveis refletem fortemente as mudanças de expectativas, sejam elas positivas sejam negativas, de alteração das regras de acesso ao benefício. Dito de outra forma, trata-se de informações atípicas, em que a demanda foi contida ou antecipada, dependendo do debate em curso na época. Além disso, a greve dos servidores do Instituto Nacional da Seguridade Social - INSS, realizada no período de agosto a novembro, certamente contribuiu para a redução da quantidade de benefícios concedidos no ano de 2001. Novamente, um fator conjuntural - agora de caráter político-sindical e na própria instituição responsável por conceder os benefícios - prejudica sua interpretação, como integrante de uma série histórica.

\section{O Desempenho das Contribuições}

Além da questão da despesa, a previdência social apresenta um grave problema no plano de sua arrecadação. Nos dois anos pós-reforma, isto é, em 2000 e 2001, a receita líquida, isto é, a arrecadação bancária das contribuições de empregados e empregadores, acrescida da receita do Simples, dos depósitos judiciais, e deduzidas as restituições de arrecadação e transferências a terceiros, foi $3,19 \%$ e 3,23\% inferior ao nível de 1986, quando o PIB brasileiro era significativamente inferior ao atual, e as alíquotas eram inferiores às atuais. Por outro lado, chama a atenção que o ritmo da queda da arrecadação está diminuindo: em relação ao ano anterior, em 1999 a retração foi de 6,67\%; em 2000, de 2,26\%; e, em 2001, de 0,05\%, o que talvez indique que ela esteja se estabilizando.

O desempenho da arrecadação da previdência social é largamente determinado pelo crescimento econômico do país e pelo comportamento do mercado de trabalho. Por isso, qualquer análise sobre a situação das contas previdenciárias, do ponto de vista da receita, precisa se reportar às mudanças nas formas de ocupação, à evolução do salário, entre outros aspectos. Da ótica da despesa, a questão demográfica aparece como fator determinante. A parte seguinte deste artigo é dedicada à análise do mercado de trabalho e do impacto da demografia na previdência social.

\section{A Questão Demográfica e o Mercado de Trabalho}

Desde a divulgação dos resultados do censo de 1991, quando pela primeira vez ficou evidente que a população brasileira crescia mais lentamente e estava ficando mais velha, as autoridades e pesquisadores da área previdenciária preocupam-se com os reflexos sobre a situação financeira do sistema público. A partir desse censo, ficava evidente para todos que o Brasil havia completado sua transição demográfica. Em 1991, a taxa de fecundidade, que era de 4,3 em 1980, havia caído para 2,4. Nove anos depois, quando novo censo é realizado, essa taxa cai para 2,2 - extremamente perto da taxa de reposição da população.

Essa nova realidade demográfica pode ser vista de várias maneiras. De um lado, já não podemos dizer, tal como na década de 70, que "somos um país jovem", quando 53\% da população tinha menos de 20 anos de idade. Em 2000, esse contingente já havia caído para $40,1 \%$ da população. Nos mesmos anos, as pessoas com mais de 65 anos repre- 
sentavam, respectivamente, $3,1 \%$ e $4,8 \%$. Em termos de esperança de vida ao nascer, o brasileiro aumentou 8,52 anos de 1970 a 2000.

Para a previdência social, contudo, o aspecto mais importante da nova realidade demográfica brasileira referese à ampliação da sobrevida, a cada faixa de idade. Assim, uma mulher com 45 anos que se aposentasse - tal como era permitido pelas regras anteriores - teria a probabilidade de permanecer no sistema por 32,04 anos; se homem, com a mesma idade, permaneceria por 27,18 anos. O tempo de permanência no sistema, em qualquer um dos casos, seria um pouco menor do que o tempo de contribuição, na hipótese de eles terem se iniciado no mercado de trabalho aos 18 anos e terem contribuído para a previdência durante toda sua vida ativa. Esse é um dos motivos que embasou a proposta do governo em introduzir, no cálculo do fator, a expectativa de sobrevida do segurado na data da aposentadoria, de substituir a aposentadoria por tempo de serviço pela de contribuição e de incluir, também, o critério de idade como condição de acesso à aposentadoria daqueles que ingressarem no mercado de trabalho depois da aprovação da lei.

Dessa forma, o Brasil iguala-se à maioria dos países com relação aos critérios de acesso à aposentadoria. O que muitas vezes não é lembrado é que o Brasil contempla múltiplas realidades em que é possível se encontrarem trabalhadores que exercem atividade no mercado formal de trabalho desde tenra idade e que serão penalizados por necessitar, não só do tempo de contribuição, mas de cumprir o critério de idade.

Além disso, é preciso destacar que, embora a população brasileira não possa ser mais chamada de "jovem" tal como na década de 70, ainda não é "velha" como as da maioria dos países europeus. No Brasil, em 2000, 64,6\% de sua população tinha idade entre 15 e 64 anos, isto é, tinha idade para trabalhar. Essa realidade seria extremamente positiva para as contas previdenciárias, mesmo se rebaixássemos o limite superior da idade de trabalho para, por exemplo, 55 anos. Ainda assim estaríamos falando de $58,7 \%$ da população.

O problema é que essa realidade só se reverte a favor da previdência social se a economia estiver gerando emprego formal, resultando em maior volume de contribuições para seu caixa. Não é essa, contudo, a nossa realidade. Além da persistência de elevadas taxas de desemprego desde o início da década de 90, aumentou significativamente a participação dos assalariados sem carteira assinada e de outros ocupados sem vínculo com a previdên- cia social. De acordo com o IBGE, o desemprego aberto chegou a atingir o pico de 8,06\% em março de 2000. Embora tenha recuado nos meses subseqüentes, encerrou o ano 2001 em 6,2\%, quase dois pontos percentuais acima da média de 1991. Já para o Dieese e para a Fundação Seade, o desemprego aberto na Região Metropolitana de São Paulo foi de 11\% em 2000, atingindo 11,3\% em 2001. A taxa de desemprego aberto, neste último ano, foi de $17,6 \%$.

A estrutura do mercado de trabalho brasileiro sofreu diretamente com o avanço do desemprego. Entre janeiro de 1991 e dezembro de 2001, a participação do trabalhador assalariado sem carteira assinada no total dos ocupados aumentou mais de seis pontos percentuais (passou de 20,8\% para 27,1\%), segundo a Pesquisa Mensal de Emprego realizada pelo IBGE. No mesmo período, houve ampliação dos chamados conta-própria (de 20,1\% passaram para $23,1 \%$ ) em três pontos percentuais, enquanto a participação da categoria empregador (de 4,4\% passou para 3,9\%) diminuiu meio ponto percentual.

Esses dados indicam que está diminuindo o tamanho relativo do mercado formal de trabalho, isto é, aquele regulamentado pelas leis trabalhistas e integrado à previdência social. Não é de estranhar, portanto, que a arrecadação de 2001, referente às contribuições de empregados e empregadores, esteja 3,2\% abaixo da receita de 15 anos atrás.

\section{CONSIDERAÇÕES FINAIS}

A nova realidade demográfica do Brasil, evidenciada no censo de 1991 e confirmada no de 2000, indicando a velocidade com que o país está envelhecendo, foi um dos principais argumentos na defesa da reforma previdenciária encaminhada pelo governo FHC. De maneira menos enfática, mas por muitos considerado como um dos aspectos que mais necessitavam de reforma, era defendida a extinção da diferença de critérios de acesso à aposentadoria entre os homens e as mulheres. Isso porque não só as mulheres, ao longo de toda sua vida, apresentavam sobrevida maior do que a dos homens, como porque esse diferencial tem crescido nas últimas décadas. É interessante mencionar que o prolongamento da vida mais acentuado entre as mulheres também é um dos determinantes da despesa com a pensão por morte, pois as mulheres constituem, de longe, a maioria que recebe esse tipo de benefício.

Apesar da intensa campanha realizada pelo governo, a proposta de utilizar o critério de idade como complemen- 
tar ao tempo de contribuição (que já havia substituído o do tempo de serviço) recebeu forte resistência dos setores mais organizados da população brasileira. Mesmo assim, pode-se dizer que o critério de idade acabou sendo incorporado na determinação da aposentadoria. No lugar de uma idade fixa para todos os homens e outra para as mulheres, adotou-se fórmula sofisticada que considera os anos de sobrevida no momento em que o segurado se aposenta. Por essa sistemática, quanto mais jovem o trabalhador se aposentar menor será o valor de seu benefício; quanto mais velho, maior o valor. Tendo em vista que o processo de envelhecimento da população brasileira está apenas em seu início, será cada vez mais difícil alguém se aposentar "precocemente".

Segundo o governo, essa mudança de regra, bem como várias outras medidas adotadas que antecederam ou acompanharam a reforma, deverá diminuir o volume da despesa com benefícios previdenciários. No caso específico da aposentadoria, o governo esperava, no curto prazo, queda acentuada do fluxo de novos beneficiários. À medida que o tempo passasse e que o estoque de aposentados do período anterior à Lei 9.876/99 fosse diminuindo, o gasto total com benefícios, isto é, das aposentadorias concedidas (novos ingressantes) e das em manutenção, também teria caído.

Contudo, a análise realizada neste artigo do número de aposentadorias concedidas pós-reforma não chegou a resultados conclusivos. Isso porque a demanda já vinha caindo antes mesmo das regras serem alteradas. Além disso, não há como se utilizar a série histórica para inferir o que seria o crescimento vegetativo da demanda - antes da Lei - para se estabelecer alguma comparação e se analisarem os resultados. Desde 1987 pelo menos, a demanda por aposentadoria ou foi deliberadamente reprimida por seus interessados, ou antecipada. Uma e outra atitude, realizadas em massa pelos trabalhadores, refletiam diferentes momentos de expectativa vivenciados pela sociedade brasileira quando da Constituição de 1988 e quando começaram as discussões sobre a necessidade de dificultar o acesso à aposentadoria e sobre a redução do tempo de permanência do trabalhador no sistema, depois de aposentado.

Se do lado da despesa a análise foi dificultada pelos motivos expostos acima, da ótica da receita o mesmo não ocorreu. Ficou bastante claro que o nível da arrecadação - inferior ao de 1986 - deve-se ao fraco desempenho da economia brasileira e, principalmente, à precarização do mercado de trabalho, onde as taxas de desemprego elevadas tornaram-se uma constante e a ocupação no mercado informal amplia-se a expensas do trabalho com carteira assinada e/ou vinculado ao sistema previdenciário. No curto prazo, portanto, a crise estrutural da previdência social poderia estar sendo resolvida se os trabalhadores em idade de trabalhar (maioria da população brasileira) estivessem em atividade, em empregos que garantissem todos os direitos trabalhistas, inclusive de contribuir para a previdência social.

\section{NOTAS}

1. Para uma análise das reformas da previdência efetuadas nos países europeus, que não descaracterizaram os fundamentos da proteção construída no pós-guerra, chamada por muitos de Welfare State, ver Marques e Mendes (2001).

2. De acordo com estudo do Ministério da Previdência Social, na "década de 50, oito contribuintes financiavam um aposentado. Em 1970, essa relação era de 4,2 para um. Nos anos 1990, são 2,3 trabalhando para um aposentado. No ano 2020, se as atuais regras forem mantidas, a proporção será de um para um” (Presidência da República,1997).

3. Os auxílios natalidade e funeral transformaram-se em benefícios assistenciais, isto é, são concedidos apenas às famílias com renda mensal per capita inferior a um quarto do salário mínimo.

4. As aposentadorias especiais permitem entrar para a inatividade com tempo de serviço menor do que o exigido para os demais trabalhadores. Era concedida para todos aqueles que trabalhavam em empresas cujas atividades são nocivas à saúde, como também para certas categorias de trabalhadores como jornalistas e aeronautas. A aposentadoria especial foi mantida exclusivamente para os trabalhadores que comprovadamente exercem atividade insalubre e/ou de risco.

5. Para se ter uma idéia , em 1996 havia no país 16,6 milhões de aposentados e pensionistas da iniciativa privada, enquanto no setor público federal eram 873 mil inativos e pensionistas (Presidência da República, 1997)

6. A fórmula de cálculo do valor da aposentadoria por tempo de contribuição é a seguinte: $\mathrm{FPR}=[(\mathrm{TC} \times \mathrm{a}) / \mathrm{Es}\} \times$ x [ 1+ (Id + Tc x a) /100], onde "TC" é o tempo de contribuição; "a" é a alíquota de contribuição do segurado (incluindo a do empregado e do empregador); "Es" é a expectativa de sobrevida do segurado na data da aposentadoria; e "Id" é a idade do segurado na data da aposentadoria (Dieese, 2001:252).

7. O déficit dos vários sistemas previdenciários em relação ao PIB em 2000 era de $4,7 \%$, assim distribuídos: $2,0 \%$ dos servidores públicos federais; $1,5 \%$ dos regimes dos servidores públicos estaduais; $0,3 \%$ dos regimes dos servidores públicos dos municípios; e $0,9 \%$ dos trabalhadores do sistema privado, ligados ao Regime Geral da Previdência Social (Brant, 2001).

8. Art. 68 da Lei Complementar $n^{\circ} 101$, de 4 de maio de 2000 (Lei de Responsabilidade Fiscal), que instituiu o Fundo do Regime Geral de Previdência Social - FRGPS, regulamenta o artigo 250 da Constituição Federal. Esse fundo é formado por bens e direitos de qualquer natureza, por aplicações financeiras e pela receita proveniente da folha de salários. As demais fontes da seguridade social, previstas no art. 195 da Constituição, não integram o fundo. Nos últimos anos, essas fontes têm sido amplamente utilizadas para cobrir o déficit da previdência (Marques; Mendes, 2001).

\section{REFERÊNCIAS BIBLIOGRÁFICAS}

BRANT, R. Reforma da previdência em um ambiente democrático. Conjuntura Social: a Previdência Social reavaliada - I. Brasília, DF: MPAS, v.12, n.2, p.65-118, abr.-jun. 2001. 
COELHO, V.S.P. A reforma da previdência e o jogo político no interior do Executivo. Novos Estudos, São Paulo, Cebrap, n. 55, p.121142, nov. 1999.

DIEESE - DEPARTAMENTO INTERSINDICAL DE ESTATÍSTICA E ESTUDOS SÓCIO-ECONÔMICOS. A situação do trabalho no Brasil. São Paulo: Dieese, 2001.

FGV - FUNDAÇÃO GETÚLIO VARGAS. Conjuntura Econômica, Rio de Janeiro, v.55, n.10, out. 2001.

FUNDAÇÃO SEADE. Anuário Estatístico do Estado de São Paulo 1999. São Paulo: 2000.

MARQUES, R.; BATICH, M. Os impactos da evolução recente do mercado de trabalho no financiamento da previdência. Pesquisa \& Debate, São Paulo, Programa de Estudos Pós-Graduados em Economia e da FEA-PUC/SP, v.10, n.2(16), p.5-29, 1999.

MARQUES, R.; MÉDICI, A. A previdência social em debate. Boletim de Conjuntura Política Social, São Paulo, Fundap, n.15, nov./dez. 1994.

MARQUES, R.; MENDES, A. A proteção social no primeiro quartel do século XXI: brincando com cenários. Análise Econômica, Porto Alegre, Faculdade de Ciências Econômicas/UFRGS, ano 18, n.33, mar. 2001.

MESA-LAGO, C. Estúdio comparativo de los costos fiscales em la transición de ocho reformas de pensiones em América Latina. In: CEPAL. Série Financiamiento del Desarrollo. Santiago do Chile: 2000.
MINISTÉRIO DA PREVIDÊNCIA E ASSISTÊNCIA SOCIAL. Anuário estatístico da Previdência Social, 1999. Brasília, DF: MPAS, 2000.

Síntese da exposição de motivos da Lei no 9.876/99. Conjuntura Social: reforma da previdência - a fase conclusiva, Brasília, DF, v.10, n.4, p.27-50, out-dez 1999.

ORNÉLAS, W. A Previdência Social sem "Caixa-Preta". Conjuntura Social: reforma da previdência - mudanças e perspectivas, Brasília, DF, MPAS, v.11, n.1, p.7-10 jan.-mar. 2000.

PRESIDÊNCIA DA REPÚBLICA. Por que reformar a Previdência? Livro Branco da Previdência Social. Brasília: Presidência da República, Secretaria de Comunicação Social, 1997.

Rosa Maria Marques: Professora do Departamento de Economia da PUC-SP e Consultora da Fundação SEADE.

Mariana Batich: Socióloga, Analista da Fundação SEADE.

ÁQuilas Mendes: Professor da Faculdade de Economia da FAAP e Técnico do Cepam. 